\title{
DESIGN, FORMULATION AND IN VITRO DRUG RELEASE FROM TRANSDERMAL PATCHES CONTAINING IMIPRAMINE HYDROCHLORIDE AS MODEL DRUG
}

\author{
SWATI HARDAINIYAN ${ }^{*}{ }^{*}$, KRISHAN KUMAR ${ }^{1}$, BANKIM CHANDRA NANDY ${ }^{2}$, RICHA SAXENA ${ }^{1}$ \\ ${ }^{1}$ Department of Agriculture, Food and Biotechnology, Jayoti Vidyapeeth Women's University, Jaipur, Rajasthan, 303122, India, \\ 2Department of Pharmaceutical Science, Jayoti Vidyapeeth Women's University, Jaipur, Rajasthan, 303122, India \\ Email: swati.pandithar@gmail.com
}

Received: 30 Dec 2016 Revised and Accepted: 03 May 2017

\begin{abstract}
Objective: The aim of the present investigation was to form matrix type transdermal patches containing imipramine hydrochloride were prepared using two polymers by solvent evaporation technique to minimise the dose of the drug for lesser side effect and increase the bioavailability of a drug.

Methods: In the present study, drug loaded matrix type transdermal films of imipramine hydrochloride were prepared by the solvent evaporation method with the help of polymers along with polyethene glycol (PEG) 400 was used as plasticizer and dimethyl sulfoxide (DMSO) was used as penetration enhancer. Drug-polymer interactions determine by FTIR and a standard calibration curve of imipramine hydrochloride was determined by using UV estimation.

Results: The formulated transdermal patch by using PVP K-30, HPMC K100M showed good physical properties. All prepared formulations indicated good physical stability. The formulation F-1 gave the most suitable transdermal film with all desirable physicochemical properties. The thickness of the patches was varied from $0.263 \pm 0.67 \mathrm{~mm}$ to $0.301 \pm 0.61 \mathrm{~mm}$, uniformity of patches showed that patches prepared by solvent evaporation while low standard deviation values ensued by thickness measurements of the film, and weights ranged between $50.5 \pm 0.75 \mathrm{mg}$ and $52.15 \pm 2.15 \mathrm{mg}$, which indicates that different batches patch weights, were comparatively similar. Folding endurance was found to be $>200$ that is satisfactory for the patches, drug content was found to be $5.33 \pm 0.14 \mathrm{mg}$ to $5.57 \pm 0.095 \mathrm{mg}$. In vitro, drug permeation studies of formulations were performed by using $\mathrm{K}-\mathrm{C}$ diffusion cells using abdomen skin of the albino rat. The results were best in in-vitro skin permeation through rat skin as compared to all other formulations prepared with a hydrophilic polymer containing permeation enhancer. The formulation, F1 is considered as the best formulation, since it shows maximum in vitro drug release as $84.71 \pm 3.07 \%$ at $24 \mathrm{~h}$. The drug release kinetics studies showed that the majority of formulations were governed by Higuchi model and mechanism of release was non-Fickian mediated.
\end{abstract}

Conclusion: In conclusion, controlled release transdermal drug delivery system (TDDS) patches of imipramine hydrochloride can be prepared using the polymer combinations, with plasticizer and enhancer. The release rate of drug through patched increased simultaneously as the concentration of hydrophilic polymer was increased. However, the mechanism of drug release of all formulations was non-Fickian. The properties of a film did not change during the period of study.

Keywords: Imipramine Hydrochloride, Transdermal patch, PVP K-30, HPMC K100M, Solvent evaporation technique, In vitro skin permeation

(C) 2017 The Authors. Published by Innovare Academic Sciences Pvt Ltd. This is an open access article under the CC BY license (http://creativecommons.org/licenses/by/4.0/) DOI: http://dx.doi.org/10.22159/ijpps.2017v9i6.16851

\section{INTRODUCTION}

Control drug release can be achieved by transdermal drug delivery system (TDDS); also known as "patches", are dosages forms designed to deliver a therapeutically effectual amount of drug throughout the skin to the systemic circulation provides a convenient route of administration for a variety of clinical indications [1]. Pharmaceutical scientists have accepted the challenge for transdermal drug delivery of the last $25 \mathrm{y}$. Most in recent times, there is an increasing detection that the skin can also supply as the port of administration for systemically active drugs. In this case, the drug applied topically will be absorbed first into blood circulation then be moved to the target tissues. This could be quite remote from the position of drug application, to achieve its beneficial purpose [2]. In recent times, it is becoming clear that the benefits of i.e. drug infusion can be closely duplicated, with no hazards, by using the skin as the port of drug administration to provide continuous transdermal drug blend into the systemic circulation.

Transdermal drug delivery makes up one of the most important routes for innovative drug delivery system. Transdermal drug delivery is a convenient, non-invasive and painless [3]. As an alternative for the oral route, transdermal drug delivery system (TDDS) allows the avoidance of gastrointestinal absorption, with its associated drawbacks of enzymatic and $\mathrm{pH}$ associated deactivation. This method also tolerates for reduced pharmacological dosing due to the shortened metabolization pathway to the transdermal route against the gastrointestinal pathway. The transdermal patch also allows stable dosing rather than the peaks and valleys in medication level connected with orally controlled medications. Multi-day therapy through an only application, quick notification of medication in the occurrence of an emergency, as well as the capacity to finish drug effects rapidly using patch removal [4]. The route of oral administration has certain disadvantages for example damage of drugs by hepatic first pass through the metabolism and enzymatic degradation in the gastrointestinal tract. Constant intravenous administration at a programmed rate has been known as a superior mode of drug delivery not only to bypass hepatic first pass effect but also to sustain a constant, extended and therapeutically effectual drug level in the body [5]. Imipramine is a tricyclic antidepressant (TCAs) which is widely used in the treatment of unipolar depression characterized by extreme sadness; despair and anhedonia. It is a white to off-white, crystalline powder; almost odourless. It is a freely soluble in water, less soluble in alcohol, sparingly soluble in acetone. The molecular formula of Imipramine hydrochloride is $\mathrm{C}_{19} \mathrm{H}_{24} \mathrm{~N}_{2}$. $\mathrm{HCl}$, it is an acyclic drug [6]. Imipramine hydrochloride (M. W. $316.87 \mathrm{~g}$ : mol) showed the favourable logarithmic value of partition coefficient (Log P (octanol/buffer pH 7.4) 2.5 and negligible skin degradation. Peak plasma levels are reached in 2 to $8 \mathrm{~h}$, and plasma half-life ranges from 9 to $24 \mathrm{~h}$ which make frequently dosing necessary to maintain the therapeutic blood levels of drug for a long-term treatment [7]. Imipramine hydrochloride is performing like generally by inhibiting the neuronal reuptake of norepinephrine and serotonin into presynaptic nerve terminals. Imipramine hydrochloride is one of the less sedating tricyclics. Imipramine hydrochloride is used for the treatment of nocturnal enuresis in 
children. Tricyclic antidepressants (TCAs) are not recommended for $6 \mathrm{y}$ of age [8]. A constant and stable plasma concentration, possible through the transdermal drug delivery system, makes this system suitable for drugs for example Tricyclic antidepressants (TCAs). Additionally, the prospect of success in therapy is improved due to better patient compliance and enhanced patient convenience. The tricyclic antidepressants (TCAs) are good applicants for transdermal drug delivery system (TDDS) because of their pharmacokinetic and pharmacodynamic properties [9]. Yet, their poor permeability and the high doses that are required present problems to delivery across the skin. For delivery of a drug, use of solvents e. g. dimethylsulfoxide (DMSO), dimethylacetamide (DMAC), etc, enhancement of permeation by tricyclic antidepressants (TCAs) through the skin. Penetration enhancers were used for their capacity to enhance the permeation of tricyclic antidepressants (TCAs) [10]. In the present study, imipramine hydrochloride was evaluated for antidepressant activity. The literature showed that this drug is being used in the treatment of depression but no scientific and research data is reported to treat depression using this drug in the form of transdermal patches. Our effort was to establish the matrix type transdermal patches containing imipramine hydrochloride and scientific data of this drug as cheap, common and affordable, effective, safe, readily available substitute antidepressant agent.

\section{MATERIALS AND METHODS}

\section{Materials}

Imipramine hydrochloride was a gifts sample from Harika Drugs Pvt. Ltd, Hyderabad, India and Hydroxy Propyl Methyl Cellulose (HPMC) K100M, Poly Vinyl Pyrrolidone (PVP) K-30, polyethylene glycol 400 (PEG) was purchased from Central Drug House Ltd., New Delhi and dimethyle sulfoxide (DMSO) was purchased from Merck, Mumbai, India.

\section{Analytical method for imipramine hydrochloride}

In this study, we follow the method given by Jadhav SB et al.,[19] with slide modification [19]. A total of $10 \mathrm{mg}$ of an accurately weighed quantity of imipramine hydrochloride was dissolved in 100 $\mathrm{ml}$ of methanol $(100 \mu \mathrm{g} / \mathrm{ml})$. From the above stock solution, $50 \mathrm{ml}$ was taken and diluted with methanol to make it $100 \mathrm{ml}$ to get the concentration of $50 \mu \mathrm{g} / \mathrm{ml}$. In order to generate a calibration curve, $5 \mu \mathrm{g} / \mathrm{ml}, 10 \mu \mathrm{g} / \mathrm{ml}, 20 \mu \mathrm{g} / \mathrm{ml}, 30 \mu \mathrm{g} / \mathrm{ml}, 40 \mu \mathrm{g} / \mathrm{ml}, 50 \mu \mathrm{g} / \mathrm{ml}$, of the primary standard were prepared and the calibration curve was obtained by measuring their absorbance at predetermined UV-VIS spectrophotometer at $251 \mathrm{~nm}$. The volumetric flask was first wrapped with black paper and then it was covered with aluminium foil to avoid the problem of drug photosensitivity.

\section{Physicochemical compatibility of drug and polymer}

The physicochemical compatibility between imipramine hydrochloride and polymers used in the films was studied by using Fourier transform infrared (FTIR) (Prestige-21, Shimadzu, and Tokyo, Japan) spectroscopy. The infrared spectra were recorded using a Fourier transform infrared (FTIR) by the potassium bromide pellet method and spectra were recorded in the wavelength region between 450 and $4000 \mathrm{~cm}^{-1}$. The spectra obtained for imipramine hydrochloride, polymers, and physical mixtures of imipramine hydrochloride with polymers were compared [19].

\section{Preparation of transdermal films}

In the present study, drug loaded matrix type transdermal films of imipramine hydrochloride were prepared by solvent evaporation method [11-13] using different ratios of Poly Vinyl Pyrrolidone (PVP) K-30 and Hydroxy Propyl Methyl Cellulose (HPMC) K100M polymers (table 1). The polymers were weighed in requisite ratios by keeping the total polymer weight at $1.0 \mathrm{gm}$ added in a solvent mixture (3:2 ratio of chloroform: methanol). Propylene glycol 400 (PEG) was incorporated as plasticizer and dimethyl sulfoxide (DSMO) as penetration enhancer were used. A known quantity of drug was added slowly to the solution and dissolved by continuous stirring for $30 \mathrm{~min}$. Solution poured onto a glass Petri dish for the formulation of transdermal patches. The disk was kept on a horizontal surface for uniformity. The solvent was allowed to evaporate for $24 \mathrm{~h}$ by inverting a funnel over a disk. The patches were cut out to give a required area for evaluation.

Table 1: Composition of transdermal patches

\begin{tabular}{llllll}
\hline Formulation code & Drug (mg) & Polymers ratio PVP K-30: HPMC K100M & DMSO & PEG 400 & Solvents ratio (Methanol: Chloroform) \\
\hline F1 & 100 & $2: 8$ & $20 \%$ & $30 \%$ & $3: 2$ \\
F2 & 100 & $4: 6$ & $20 \%$ & $30 \%$ & $3: 2$ \\
F3 & 100 & $8: 4$ & $20 \%$ & $30 \%$ & $3: 2$ \\
F4 & 100 & $20 \%$ & $30 \%$ & $3: 2$ \\
\hline
\end{tabular}

\section{Evaluation of transdermal patches of imipramine hydrochloride}

Physicochemical properties such as physical appearance, thickness, weight variation [12], folding endurance [14], moisture uptake [15], were determined on developed patches.

\section{In vitro permeation study}

Animal studies was conducted according to the Institutional Animal Ethics Committee (IAEC) guidelines and all the animals were used and care as per the norms stated in Institutional Animal Ethics Committee (IAEC) guidelines, in Jayoti Vidyapeeth Women's University, Jaipur, with due permission from Institutional Animal Ethics Committee (IAEC) (R. No. 1402/a/10/CPCSEA). Adult male Swiss Albino mice weighing 25-35 g which was purchased from Indian Veterinary Research Institute, Izzatnagar, and Bareilly Uttar Pradesh were used in this study. The animals were housed at $24 \pm 2^{\circ} \mathrm{C}$ with $12: 12 \mathrm{~h}$ light and dark cycle. They had free access to food and water ad libitum. The in vitro permeation study of transdermal patches of imipramine hydrochloride was carried out by using excised rat abdominal skin and KC diffusion cell [16]. The skin was sandwiched between donor and receptor compartments of the diffusion cell. The patch of $1 \mathrm{~cm}^{2}$ was placed in intimate contact with the stratum corneum side of the skin; the top side was covered with aluminium foil as a backing membrane. Teflon bead was placed in the receptor compartment filled with $25 \mathrm{ml}$ of buffer solution (PBS pH 7.4). The cell contents were stirred with a magnetic stirrer and a temperature of $37 \pm 0.5{ }^{\circ} \mathrm{C}$ was maintained throughout the experiment. Samples of $1 \mathrm{ml}$ were withdrawn through the sampling port at different time intervals for a period of $9 \mathrm{~h}$, simultaneously replacing equal volume by phosphate buffer $\mathrm{pH} 7.4$ after each withdrawal. The samples were analyzed spectrophotometrically at $251 \mathrm{~nm}$.

\section{Stability studies}

Optimised medicated films were subjected to short term stability testing. Films were placed in a Petri disk lined with aluminium foil and kept in a humidity chamber (desiccators) maintained at $40 \pm 2{ }^{\circ} \mathrm{C}$ and $75 \pm 5 \%$ RH (under Accelerated condition) for 3 mo as per ICH guidelines [17] Changes in the appearance and drug content of the stored films were investigated after storage at the end of last month.

\section{RESULTS}

\section{Evaluation of transdermal patch}

For the study of the analytical method of imipramine hydrochloride, a standard curve was prepared and the calibration curve was obtained by measuring their absorbance at predetermined UV-VIS spectrophotometer at $251 \mathrm{~nm}$. The resulting solution containing $10 \mu \mathrm{g} / \mathrm{ml}$ was scanned between 200 to $800 \mathrm{~nm}$. The spectrum is given in fig. 1(a). The $\lambda_{\max }$ was found to be $251 \mathrm{~nm}$ and was used as analytical wavelength. The value matches with the literature [19] value of $251 \mathrm{~nm}$. The absorbance of these drug solutions was estimated at $\lambda_{\max } 251 \mathrm{~nm}$. 
The procedure was performed in triplicate to validate the calibration curve. A calibration curve was constructed and shown in fig. 1(b).

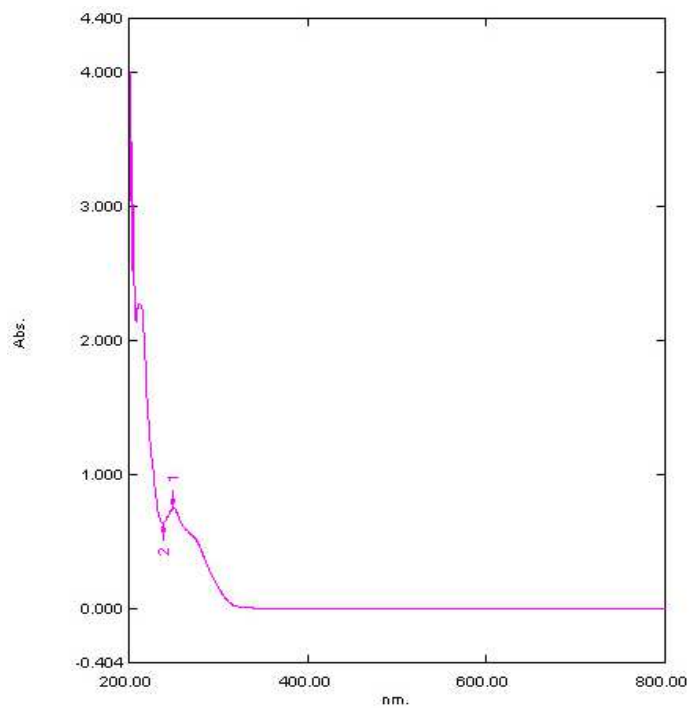

Fig. 1(a): UV scans of imipramine hydrochloride in methanol

The prepared transdermal patches were evaluated for their physicochemical properties such as appearance, thickness, folding endurance, drug content, weight variation (table 2) and in vitro drug permeation through albino rat skin (table 3). FTIR studies showed characteristic peaks of imipramine hydrochloride, confirming the purity of the drug (fig. 3).

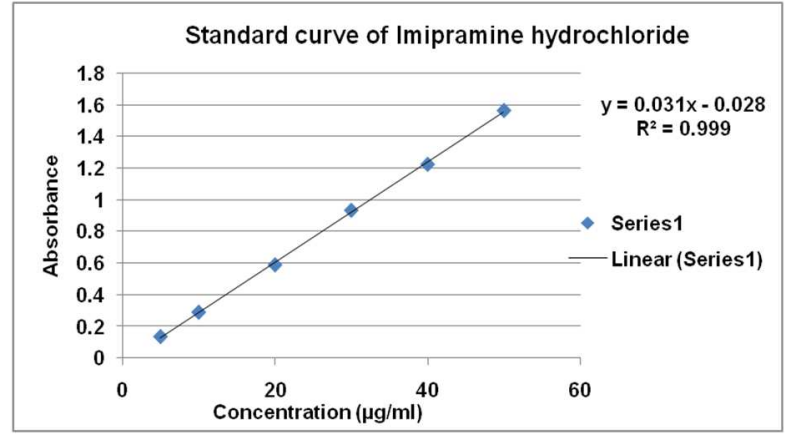

Fig. 1(b): Standard curve of imipramine hydrochloride in methanol

The physical form of the different formulations in terms of their transparency, flexibility, smoothness, stickiness, homogeneity and dense properties was recorded. The formulation F-1 was found to be thin, transparent, uniform, flexible and good folding endurance formulation F-2 was found to be thin, uniform, transparent and flexible, formulation F-3 was found to be thin, opaque and flexible and formulation F-4 was found to be thick, not flexible and opaque. The formulation F-1 gave the most suitable transdermal film with all desirable physicochemical properties. The thickness of the patches was varied from $0.263 \pm 0.67 \mathrm{~mm}$ to $0.301 \pm 0.61 \mathrm{~mm}$. The uniformity of patches showed that patches prepared by solvent evaporation while low standard deviation values ensued by thickness measurements of the film. The weights ranged between $50.5 \pm 0.75$ $\mathrm{mg}$ and $52.15 \pm 2.15 \mathrm{mg}$, which indicates that different batches patch weights, were comparatively similar. Folding endurance was found to be 200 that are satisfactory for the patches, drug content was found to be $5.33 \pm 0.14 \mathrm{mg}$ to $5.57 \pm 0.095 \mathrm{mg}$.

Table 2: Physiochemical evaluation of transdermal patches

\begin{tabular}{|c|c|c|c|c|}
\hline Formulation code & F1 & F2 & F3 & F4 \\
\hline Appearance & $\begin{array}{l}\text { Thin, uniform, transparent, flexible } \\
\text { and good folding endurance }\end{array}$ & $\begin{array}{l}\text { Thin, uniform, transparent } \\
\text { and flexible }\end{array}$ & $\begin{array}{l}\text { Thin, opaque and } \\
\text { flexible }\end{array}$ & $\begin{array}{l}\text { Thick, not flexible and } \\
\text { opaque }\end{array}$ \\
\hline Thickness $( \pm \mathrm{SD})$ & $0.263 \pm 0.67$ & $0.28 \pm 0.031$ & $0.27 \pm 0.026$ & $0.301 \pm 0.61$ \\
\hline Weight (mg) $( \pm \mathrm{SD})$ & $51.01 \pm 0.80$ & $50.5 \pm 0.75$ & $52.15 \pm 0.68$ & $52.02 \pm 2.15$ \\
\hline $\begin{array}{l}\text { Drug content }( \pm \text { SD }) \\
(2.64 \mathrm{~cm} 2 / \mathrm{mg})\end{array}$ & $5.33 \pm 0.14$ & $5.47 \pm 0.12$ & $5.35 \pm 0.11$ & $5.57 \pm 0.095$ \\
\hline Folding endurance & $>200$ & $>200$ & $>200$ & $>200$ \\
\hline
\end{tabular}

All values mentioned as mean $\pm S D,(n)=3$

The cumulative percentage drug permeated and percentage drug retained by the individual path in the in vitro skin permeation studies were based on the mean amount of drug present in the respective patch. The cumulative percentage drug release for F-1 was found to be $84.71 \pm 3.07 \%$ at $24 \mathrm{~h}$ and for $\mathrm{F}-4$ it was found $50.91 \pm 2.07 \%$ at $24 \mathrm{~h}$. The formulation, F-1 [HPMC K100M, PVP K-30 (8:2)] is considered as the best formulation since it shows maximum in vitro drug release as $84.71 \pm 3.07 \%$ at $24 \mathrm{~h}$.

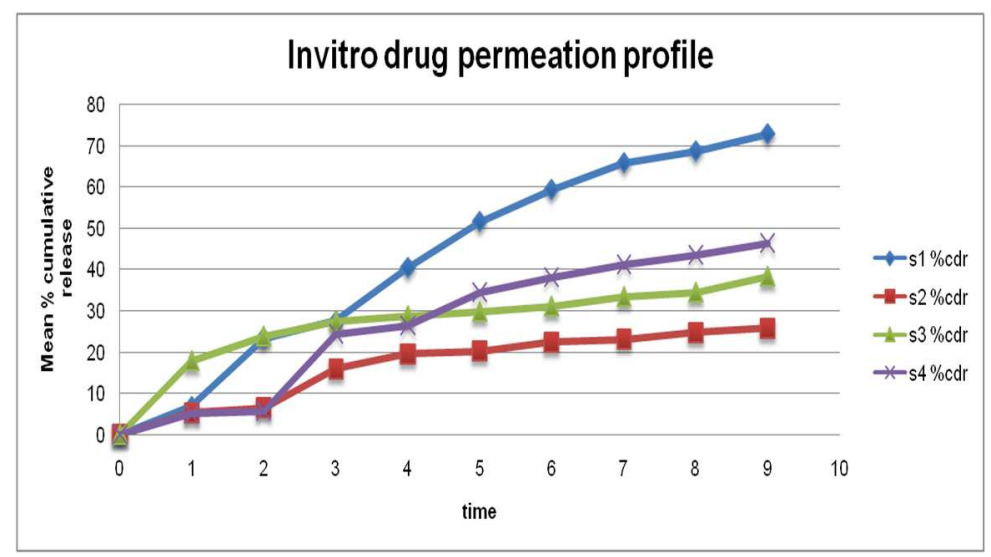

Fig. 2: Comparative drug permeation profile 
Table 3: In vitro drug permeation profile of Imipramine hydrochloride transdermal patches

\begin{tabular}{lllll}
\hline Formulation code & Zero order (R2) & First order (R2) & Higuchi (R2) & Korsmeyer peppas (R2) \\
\hline F1 & 0.971 & 0.992 & 0.988 & 0.960 \\
F2 & 0.894 & 0.884 & 0.926 & 0.906 \\
F3 & 0.764 & 0.944 & 0.963 & 0.973 \\
F4 & 0.937 & 0.948 & 0.951 & 0.893 \\
\hline
\end{tabular}

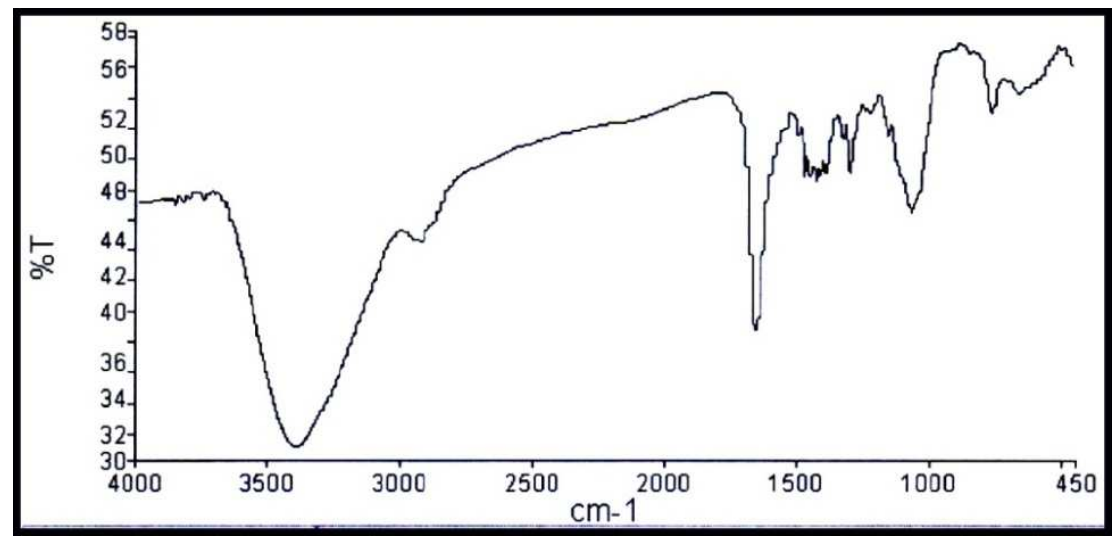

Fig. 3: FTIR spectra of imipramine hydrochloride with polymers

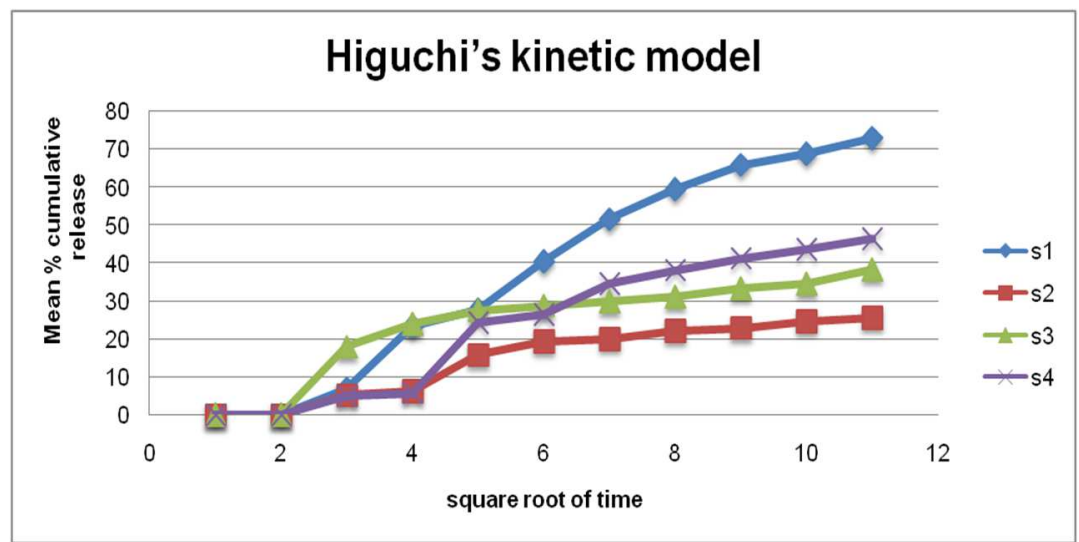

Fig. 4: Higuchi's kinetic profile

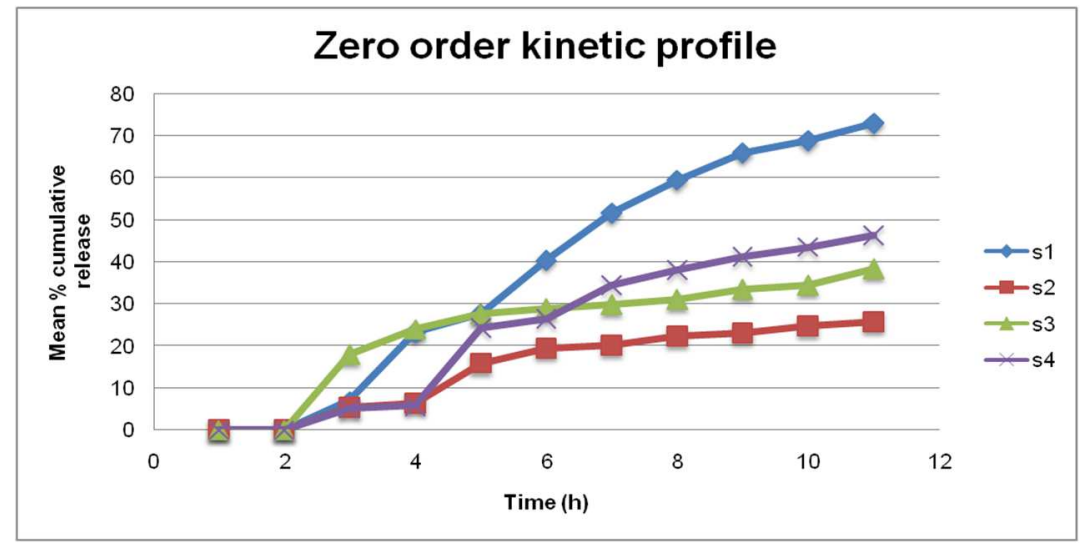

Fig. 5: Zero order kinetic profile

Stability studies of the selected patch was performed under accelerated $\left(40{ }^{\circ} \mathrm{C}\right.$ and $\left.75 \% \mathrm{RH}\right)$ conditions. The test result of the study for the formulation F-1 presented in table 4. The physical stability of imipramine hydrochloride transdermal patch proved to be unchanged after storage up to 3 mo under accelerated conditions at $40{ }^{\circ} \mathrm{C} / 75 \% \mathrm{RH}$. The result obtained for the test item "appearance" was not changed significantly. Significant changes in physical and chemical stabilities were not observed. Because the accelerated data show little or no change over time and little variability so, a statistical analysis was considered unnecessary. 
Table 4: Summary of physicochemical properties of F-1 patches before and after stability studies

\begin{tabular}{lll}
\hline Studies parameter & Before stability studies & After stability studies (90 d) \\
\hline Thickness & $0.263 \pm 0.67$ & $0.263 \pm 0.58$ \\
Folding endurance & $>200$ & $>198$ \\
Drug content & $5.33 \pm 0.14$ & $5.32 \pm 0.38$ \\
Physical appearance & Transparent white and flexible & Transparent white to off-white and flexible \\
\hline
\end{tabular}

All values mentioned as mean $\pm S D,(n)=3$

\section{DISCUSSION}

Transdermal drug delivery system (TDDS) enhances the bioavailability of the drug by avoiding the first pass metabolism and increases the therapeutic efficacy of the drug by reaching into the systemic circulation. This is the most suitable system for a long term treatment or for a multi-dose treatment because transdermal patches are prepared for a long period of time in a single dose providing treatment from a day to even up to seven days. Polymers hydroxypropyl methyl cellulose (HPMC K100M) and polyvinyl pyrrolidone (PVP K-30) were selected on the basis of their adhering property and nontoxicity. The result of the study showed good controlled release. The result from present study concluded that imipramine hydrochloride in combination with hydroxypropyl methyl cellulose (HPMC K100M), polyvinyl pyrrolidone (PVP K-30) and with an incorporation of polyethylene glycol (PEG) 400 (30\%) and dimethyl sulfoxide (DMSO) (20\%) produced a smooth, flexible and transparent film. FTIR studies showed characteristic peaks of imipramine hydrochloride, confirming the purity of the drug. FT-IR spectral studies indicated there was no interaction between imipramine hydrochloride and polymers used (fig. 3).

Imipramine hydrochloride patches were prepared with the combination of polymers and evaluated it for physical parameters such as thickness, drug content, weight variation, \% moisture loss and \% moisture absorption. It was observed from this result, that thickness, weight variation, drug content, low moisture loss, low moisture absorption, were suitable for maximum stability of the prepared formulations. The drug content of transdermal drug delivery system (TDDS) patches ranged from $5.33 \pm 0.14 \mathrm{mg}$ to $5.57 \pm 0.095 \mathrm{mg}$. The drug releases rate increased as the concentration of hydrophilic polymer was increased. The cumulative percentage drug release for F1 was found to be $84.71 \pm 3.07 \%$ at $24 \mathrm{~h}$ and for F4 it was found $50.91 \pm 2.07 \%$ at $24 \mathrm{~h}$. The formulation, F1 is considered as the best formulation, since it shows maximum in vitro drug release as $84.71 \pm 3.07 \%$ at $24 \mathrm{~h}$. The drug release kinetics studies showed that the majority of formulations were governed by Higuchi model and mechanism of release was non-Fickian mediated. Higuchi developed an equation for the release of a drug from a homogeneous polymer matrix-type delivery system that indicates a number of drug releases are proportional to the square root of time [18]. When plotted against the square root of time, the release of drug from the transdermal film showed a straight line, it indicates that the release pattern is obeying Higuchi's kinetics. In our experiments, in vitro releases profiles of all the different formulations of transdermal patches could be best expressed by Higuchi's equation, for the release of drug from a homogeneous polymer matrix-type delivery system that depends mostly on diffusion characteristics. From the in vitro permeation profile data of all the formulations through rat skin, kinetics of drug release were found for zero-order, first-order, Higuchi-type release kinetics and Korsmeyer-peppas-type release kinetics. The coefficient of correlation (R2) of each of these releases kinetics was calculated and compared (table 3). The data revealed that the release pattern of selected formulations was best fitted for Higuchi kinetics (fig. 4), as the formulation coefficient values predominate over zero-order (fig. 5), first-order and Korsmeyer-peppas type release kinetics, which again confirmed with Higuchi's equation for the drug release from the matrix. Thus, a slow and controlled release as observed is indicating that the drug release mechanism is non-fickian model, as proposed by Higuchi.

The regression analysis of the in vitro permeation curves was carried out for in vitro permeation studies in rat skin. Among all these formulations, the formulation F-1 showed the maximum \% drug cumulative release i.e. $84.71 \%$ up to $24 \mathrm{~h}$ of the study. All the formulations showed Higuchi-type release kinetics. Regression analyses of the in vitro permeation curves were carried out.

The in vitro release data were fitted to models representing zeroorder, first-order, and Higuchi's square root of time to determine the correlation coefficient, slope, and intercepts values. From the values of the correlation coefficients, the best-fitted data can be predicted. The curve fitting of the release data was carried out mainly by regression analysis [20]. The maximum correlation coefficient has been considered statistical parameter to designate the function with the best fit to the data [21]. The inspection of correlation coefficient values showed that the drug release followed the diffusion control mechanism from the patches [22-23]. The study of Jadhav SB [19] et al., (2014) showed that the stability studies were carried out at 25 ${ }^{\circ} \mathrm{C} / 60 \% \mathrm{RH}$ for the selected formulation up to $30 \mathrm{~d}$. in the duration of stability study time interval, the tablets were analyzed for drug hardness, in vitro disintegration time, \% drug release up to $30 \mathrm{~d}$. These formulations show not much difference in any parameter. This study was concluded that the formulation was stable and retained their original properties [19].

\section{CONCLUSION}

In conclusion, controlled release transdermal drug delivery system (TDDS) patches of imipramine hydrochloride can be prepared to use the polymer combinations, hydroxypropyl methyl cellulose (HPMC K100M), polyvinyl pyrrolidone (PVP K-30) (8:2) with polyethylene glycol (PEG) 400 and dimethyl sulfoxide (DMSO) as plasticizer and enhancer, respectively. The release rate of a drug throughout patched increased at the same time as the concentration of hydrophilic polymer was increased. However, the mechanism of drug release of all formulations was non-fickian. The properties of a film did not change during the period of study. Further, in vivo studies have to be performed to correlate with in vitro release data for the development of appropriate controlled release patches for imipramine hydrochloride. Because the accelerated data show little or no change over time and little variability so, a statistical analysis was considered unnecessary.

\section{ACKNOWLEDGEMENT}

Authors are grateful to Harika Drugs Pvt. Ltd, Hyderabad, for providing gift samples of Imipramine Hydrochloride and Jayoti Vidyapeeth Women's University, Jaipur for providing necessary lab facilities.

\section{CONTRIBUTION OF AUTHORS}

The first, third and fourth author have participated in the work including participation in the concept, design, analysis, writing, and revision of the manuscript. The second and third author gave the valuable guidance and essential knowledge in this whole work.

\section{CONFLICT OF INTERESTS}

Authors hereby declare that there was no conflict of interests in the accomplishment of this study.

\section{REFERENCES}

1. Kumar JA, Pullakandan N, Prabu SL, Gopal V. Transdermal drug delivery system: an overview. Int J Pharm Sci Rev Res 2010;3:49-53.

2. Singh JV, Singh SJ, Sharma AK, Gilhotra RM, Sharma A, Jat RK. Design, formulation and in vitro drug release from transdermal 
patches containing Nebivolol hydrochloride as model drug. Asian J Pharm Res 2012;2:136-41.

3. Kooriyattil N, Sajeeth CI, Santhi K. Formulation, optimization and evaluation of matrix-type of transdermal system of simvastatin using permeation enhancers. Int J Curr Pharm Res 2012;4:79-87.

4. Latha S, Selvamani P, Thirunavukkarasu C, kadambavadani R. Formulation development and comparison in the evaluation of a transdermal drugs delivery system for anti-emetic therapy. Int J Res Pharm Biomed Sci 2011;2:525-8.

5. Costa P, Ferreria DC, Morgado R, Sousa Lobo JM. Design and evaluation of the alorazepam transdermal delivery system. Drug Dev Ind Pharm 1997;23:939-44.

6. Hardman JG, Limbird LE, Goodman Gilman A. Goodman and Gilmans: The Pharmacological Basis of Therapeutics. 10th ed. New York: The McGraw Hill Companies; 2001. p. 399-428, 450-77.

7. Reddy G, Ramesh C, Narayana T, Rao K, Rao B. Development of ion-association methods for spectrophotometric assay of imipramine hydrochloride. Int J Chem Sci 2011;9:457-64.

8. Maj J, Miroslawa M, Ewa M, Wladyslawa D. Different pharmacokinetic and pharmacological effects following acute and chronic treatment with imipramine. J Neu Trans 1982;54:219-28.

9. Jainy AK, Panchagnula R. Transdermal delivery of imipramine hydrochloride: development and evaluation (in vitro and in vivo) of reservoir gel formulation. Biopharm Drug Dispos 2005;26:41-9.

10. Stott PW, Williams AC, Barry BW. Characterization of complex coacervates of some tricyclic antidepressants and evaluation of their potential for enhancing transdermal flux. J Controlled Release 1996;41:215-27.

11. Sivakumar T, Selvam PR, Singh AK. Transdermal drug delivery systems for antihypertensive drugs-a review. Int J Pharm Biomed Res 2010;1:1-8

12. Kaur T, Gill B, Kumar S, Gupta GD. Design and development of hydroxypropyl methycellulose (HPMC) based polymeric films of sertraline hydrochloride: physicochemical, in vitro and in vivo evaluation. Innovations Pharm Pharmacother 2013;1:103-16.

13. Gupta JRD, Tripathi P, Irchhiaya R, Garud N, Dubey P, Patel JR. Formulation and evaluation of matrix type transdermal patches of glibenclamide. Int J Pharm Sci Drug Res 2009;1:46-50.
14. Devi VK, Saisivam S, Maria GR, Deepti PU. Design and evaluation of matrix diffusion controlled transdermal patches of verapamil hydrochloride. Drug Dev Ind Pharm 2003;29:495503.

15. Mutalik S, Udupa N. Glibenclamide transdermal patches: physicochemical, pharmacodynamic, and pharmacokinetic evaluations. Pharma Sci 2004;93:1577-94.

16. Shinde AJ, Garala KC, More HN. Development and characterization of transdermal therapeutics system of tramadol hydrochloride. Asian J Pharm 2008:2:265-9.

17. Mathews BR. Regulatory aspects of stability testing in Europe. Drug Dev Ind Pharm 1999;25:831-56.

18. Chien YW. Controlled drug delivery fundamentals and application. 2nd Ed. Robinson JR, Lee VHL. Eds. Marcel Dekker, Inc. New York; 1987. p. 39-55.

19. Jadhav SB, Mali AD, Rajeghadage SH, Bathe RS. Formulation and evaluation of immediate release tablets of imipramine hydrochloride. Int I Biomed Adv Res 2014;5:559-65.

20. Akbuga J, Bergisadi N. Effect of drug properties on physical and release characteristics of eudragit microspheres prepared by spherical crystallization technique. Drug Dev Ind Pharm 1997;23:407-41.

21. Bosca MMT, Hinojosa OJ, Claramonte CMD, Salem II. Statistical comparison of two methods of dissolution of sustained-release theophylline tablets. Drug Dev Ind Pharm 1996;22:595-60.

22. Siepmann J, Peppas NA. Modeling of drug release from delivery systems based on hydroxypropyl methylcellulose (HPMC). Adv Drug Delivery Rev 2001;48:139-57.

23. Zuleger S, Lippold BC. Polymer particle erosion controlling drug release. I. Factors influencing drug release and characterization of the release mechanism. Int J Pharm 2001;217:139-52.

\section{How to cite this article}

- Swati Hardainiyan, Krishan Kumar, Bankim Chandra Nandy, Richa Saxena. Design, formulation and in vitro drug release from transdermal patches containing imipramine hydrochloride as model drug. Int J Pharm Pharm Sci $2017 ; 9(6): 220-225$ 